\title{
Mechanism of Phage-induced Lysis in Pneumococci
}

\author{
By PEDRO GARCIA, ${ }^{1}$ RUBENS LOPEZ, ${ }^{1}$ CONCEPCION RONDA, ${ }^{1}$ \\ ERNESTO GARCIA ${ }^{1}$ AND ALEXANDER TOMASZ ${ }^{2 *}$ \\ ${ }^{1}$ Instituto de Inmunologia y Biología Microbiana (CSIC), Madrid, Spain \\ ${ }^{2}$ The Rockefeller University, 1230 York Avenue, New York 10021, U.S.A.
}

(Received 19 May 1982; revised 29 July 1982)

\begin{abstract}
Earlier studies have suggested the possible role of host autolytic enzyme in the release of progeny phage from Dp-1 infected pneumococci. Several new experiments described here reinforce this notion. Specifically, the resistance of an autolysis-defective mutant to infection at low phage to cell ratios could be eliminated by prior 'coating' of the host bacteria with pneumococcal autolysin isolated from wild-type cells. Similar, productive infection was also possible by lowering the temperature of incubation to $30^{\circ} \mathrm{C}$, a condition that leads to a partial activation of the thermosensitive residual autolysin in the mutant cells. Other experiments, however, clearly indicate the role of the newly discovered phage-associated lysin (PAL), reported in the accompanying communication, in bacteriophage release and culture lysis; specifically, lysis was stimulated by reducing agents and inhibited by cardiolipin. It seems that both the host-related and the PAL activities are involved with Dp-1 induced lysis of pneumococci.
\end{abstract}

\section{INTRODUCTION}

One of the interesting aspects of the pneumococcal phage Dp-1 is the apparent role of host murein hydrolase activity in the release of progeny phage particles (Höltje \& Tomasz, $1976 b$; Ronda et al., 1977). This notion has been based on the resistance of autolysis-defective pneumococcal mutants to phage infection and phage-induced lysis. Suppression of the autolytic system may be achieved by growth of host pneumococci in ethanolamine-containing medium (Tomasz \& Westphal, 1971), growth at low pH, or in the presence of trypsin or Forssman antigen added to the growth medium (Höltje \& Tomasz, 1975; Ronda et al., 1977). Also, an autolysisdefective pneumococcal mutant containing less than $1 \%$ of the bacterial murein hydrolase activity was resistant to infection by $\mathrm{Dp}-1$, if exposure to the phage was performed at low multiplicities of infection (m.o.i. <1) (Ronda et al., 1977). Such cultures could be resensitized to infection by adsorbing wild-type murein hydrolase on to the surface of the mutant cells prior to infection (Lopez et al., 1981). All these observations suggested that triggering of host autolytic activity by some phage product may be required for the escape of progeny phage from the host bacteria. However, these studies also yielded a puzzling observation: namely, that complete lysis of the autolysis-defective mutant culture could be achieved after infection at higher phage to cell ratios (m.o.i. $>1$ ). A closer examination of the phage lysates of such mutant cultures resulted in the detection of a murein hydrolase activity that differed in several respects from the properties of the wild-type pneumococcal murein hydrolase (Garcia et al., 1982).

The purpose of the present investigation was to examine the role of this new phage-associated hydrolase activity in the lysis and release of progeny phage from both the autolysis-defective and the wild-type pneumococci. In addition, some results suggested that this phage associated murein hydrolase may replace the defective host autolysin in making the mutant bacteria sensitive to autolysis. 


\section{METHODS}

Micro-organisms. Streptococcus pneumoniae R6, a derivative of the Rockefeller University Laboratory wild-type strain R36A, was used as the wild-type strain. Strain $c w 1$ is a mutant of R6 defective in the major autolysin ( $N$ acetyl-muramyl-L-alanine amidase) present in the wild type (Lacks, 1970). Bacteria with teichoic acids containing choline or ethanolamine residues were produced by growth for more than 20 generations in synthetic medium supplemented with the appropriate amino alcohol, as previously described (Tomasz et al., 1975). The isolation and purification of bacteriophage Dp-1 has been published elsewhere (Lopez et al., 1977). Chemically defined (Cden) growth medium, semisynthetic (C) medium (Tomasz, 1966, 1970), C medium supplemented with yeast extract $\left(\mathrm{C}+\mathrm{Y}\right.$; Difco yeast extract, final concentration $50 \mu \mathrm{g} \mathrm{ml}^{-1}$ ), and the preparation of autolysin (Höltje \& Tomasz, $1976 \mathrm{~b}$ ) have been described in detail in previous communications.

The coating of mutant bacterium $(c w l)$ with wild-type autolysin and the testing of sensitivity to deoxycholate (DOC)-induced lysis, were carried out as described previously (Tomasz \& Waks, 1975; Tomasz et al., 1975).

Cell walls of choline-grown bacteria labelled with [methyl ${ }^{3} \mathrm{H}$ ]choline (specific activity $60-90 \mathrm{Ci} \mathrm{mmol}^{-1}, 2 \cdot 2-$ 3.3 $\mathrm{TBq} \mathrm{mmol}{ }^{-1}$, Amersham) were prepared from mid-exponential phase cultures (Mosser \& Tomasz, 1970). All chemicals used were commercially available (analytical grade) reagents. Benzylpenicillin (potassium salt) was obtained from Eli Lilly Corp.

Release of macromolecular choline-labelled material from bacteria infected with $D p-1$. A culture of $c w 1$ in $\mathrm{C}+\mathrm{Y}$ medium was grown for three generations in the presence of radioactive choline $\left(\left[\right.\right.$ methyl $\left.{ }^{3} \mathrm{H}\right] \mathrm{choline} 2 \mu \mathrm{Ci}$ and $\left.5 \mu \mathrm{g} \mathrm{m}^{-1}\right)$. The culture was centrifuged and resuspended in $\mathrm{C}+\mathrm{Y}$ medium. At a concentration of $6.2 \times 10^{7}$ c.f.u. $\mathrm{ml}^{-1}$ half of the culture was infected with Dp-1 (m.o.i. $=2$ ). After 20 min, excess virus was removed by centrifugation and half of the culture was transferred to fresh growth medium. The other half of the culture received the same treatment except that it was not infected with Dp-1. Growth was followed by the usual nephelometric procedure. Samples were removed to quantify the total macromolecular radioactivity (i.e. precipitable by cold trichloroacetic acid) in both infected and uninfected cultures.

Sensitization of $D p-1$ infected $c w 1$ to exogenous autolysin. Bacteria were pre-labelled with radioactive choline and half of the culture was infected with $\mathrm{Dp}-1$. At various times during incubation pairs of samples $(0.9 \mathrm{ml}$ each) were removed from each of the two cultures. One sample received $100 \mu \mathrm{l}$ crude autolysin prepared from wild-type cells [about $10^{9}$ cell equivalents of enzyme activity (Höltje \& Tomasz, 1976a)]; the other received $100 \mu 10 \cdot 1 \mathrm{M}$ sodiumphosphate buffer (pH 7.0). After $5 \mathrm{~min}$ incubation at $37^{\circ} \mathrm{C}$ these samples were centrifuged $(10000 \mathrm{~g}, 5 \mathrm{~min}$, Eppendorf microcentrifuge) and the radioactivity released into the supernatant was determined.

The sedimented bacteria were next resuspended in $500 \mu 12 \%(\mathrm{w} / \mathrm{v})$ SDS solution and were heated at $80^{\circ} \mathrm{C}$ for $30 \mathrm{~min}$. After cooling to room temperature, the SDS-treated bacteria were centrifuged, pellets washed and resuspended in water $(10000 \mathrm{~g}, 10 \mathrm{~min}$, in Eppendorf microcentrifuge) and the fraction of radioactivity that remained insoluble in hot SDS (i.e. radiolabelled murein material) was determined.

\section{RESULTS}

\section{Dependence on m.o.i. of phage-induced lysis and release of progeny phage in the} autolysis-defective mutant $\mathrm{cwl}$

In contrast to the infection of the autolysis-prone wild-type cells (R6) which underwent lysis and liberated the expected crop of progeny phage independent of the m.o.i. (see Fig. 1, curve E), mutant cultures underwent phage-induced lysis only if Dp-1 infection was initiated at high phage to cell ratios (m.o.i. >1) (Fig. 1, curve D).

This dependence on m.o.i. was apparently related to the condition of the host autolytic system since mutant bacteria 'coated' with wild-type autolysin (Tomasz \& Waks, 1975) prior to exposure to the low m.o.i. of Dp-1, underwent normal lysis (Fig. 1, curve C). The second surprising feature of these experiments was the apparently normal lysis (and release of progeny phage) in the $c w 1$ culture infected with a high m.o.i. of Dp-1 (Fig. 1, curve D). This latter finding contrasted sharply with observations (data not given) which indicated that this mutant did not undergo lysis after treatment with a variety of autolysis inducing agents, such as detergents, hypertonic medium and cell wall inhibitory antibiotics. Biochemical assays showed that the mutant cells contained only a small fraction $(<1 \%)$ of the specific murein hydrolase activity characteristic of wild-type pneumococci (Jiang \& Tomasz, 1981). The inhibition of phageinduced lysis at low m.o.i. could be easily prevented by adding a reducing agent (10 mM-DTT) to the growth medium (data not given).

Another remarkable change in the $c w 1$ cells brought about by infection with Dp-1 at high m.o.i. is shown in Fig. 2. Uninfected $c w 1$ cells were completely resistant to detergent-induced 


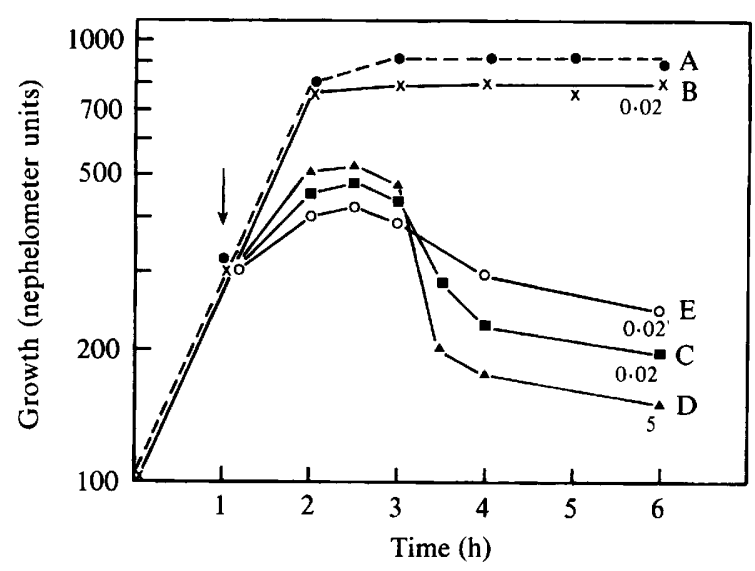

Fig. 1. Phage-induced lysis of autolysin-defective and wild-type cultures as a function of the m.o.i. Both the mutant (curve B, $\times$ and $\mathrm{D}, \boldsymbol{A}$ ) and the wild-type (curve $\mathrm{E}, \mathrm{O}$ ) cultures were grown in $\mathrm{C}+\mathrm{Y}$ medium. Cells were infected at the time indicated by the arrow, at the m.o.i. values indicated by the numbers on the curves. In addition, an exponentially growing culture of lysis-defective cells (deficient in murein hydrolase) was coated with purified pneumococcal autolysin $\left[10^{9}\right.$ cell equivalents (ml medium $)^{-1}$ ] as described in Tomasz \& Waks (1975). After $30 \mathrm{~min}$ the culture was divided into two portions: one was incubated without any addition (curve $A, O$ ) and the other received phage Dp-1 (m.o.i. 0.02) (curve C, $\square$ ). Growth and lysis were monitored by an observation of the turbidity of the cultures in a nephelometer. The figure represents one typical case of many similar experiments.

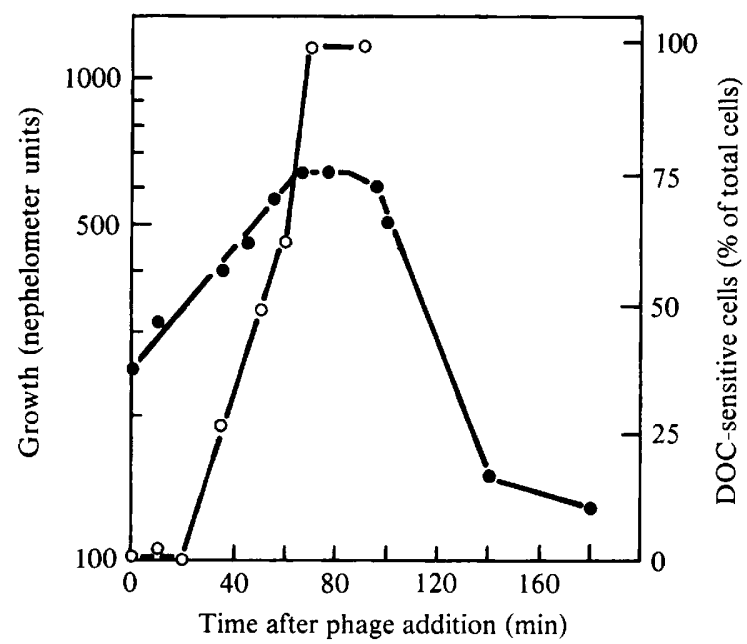

Fig. 2. Sensitivity to lysis by deoxycholate (DOC) of $c w l$ cells infected with phage Dp-1; $c w 1$ mutant organisms were grown in $\mathrm{C}+\mathrm{Y}$ medium and infected with $\mathrm{Dp}-1(\mathrm{~m} . \mathrm{o.i} .=5)$ at a cell density of $6.2 \times 10^{7}$ c.f.u. $\mathrm{ml}^{-1}$. Growth was followed by nephelometry (O). Sensitivity to DOC-induced lysis (O) was determined at different times as previously reported (Tomasz et al., 1975). 100\% indicates complete lysis. Data represent mean values of three experiments.

lysis (Lacks, 1970), whereas Dp-1 infected cultures of $c w 1$ became rapidly sensitized to lysis by DOC. Since detergent-induced lysis of wild-type pneumococci is known to be caused by the triggering of a murein hydrolase, the observation illustrated in Fig. 2 strongly suggested the appearance of a hydrolase activity in the infected culture. Indeed, lysis (measured as drop of turbidity) of $c w 1$ culture infected with high m.o.i. of $\mathrm{Dp}-1$, was accompanied by the gradual degradation of cell wall material which extended to close to $90 \%$ of the cell wall by completion of lysis. 


\title{
Table 1. Assay of phage-associated lysin activity
}

\begin{abstract}
The assay for lytic activity induced by the phage $\mathrm{Dp}-1$ in $c w 1$ was similar to that previously described for the pneumococcal amidase (Höltje \& Tomasz, 1976a). A sample $(10 \mu \mathrm{l})$ of $\left[{ }^{3} \mathrm{H}\right]$ choline cell walls $\left(0.15 \mathrm{mg}\right.$ dry wt ml $\mathrm{m}^{-1} ; 10^{6}$ c.p.m. $\mathrm{ml}^{-1}$ ) and $100 \mu 1$ lysate (for experiments $2-5$ ) or $10 \mu \mathrm{l}$ (for experiment 1) plus $100 \mu \mathrm{l} 0.02 \mathrm{M}$-phosphate buffer, $\mathrm{pH} 6.9$ were incubated for $1 \mathrm{~h}$ or $4 \mathrm{~h}$ at $37^{\circ} \mathrm{C}$. The reaction was stopped by adding $20 \mu \mathrm{l}$ or $38 \%(\mathrm{v} / \mathrm{v})$ formaldehyde and $20 \mu \mathrm{l} 0.4 \%(\mathrm{w} / \mathrm{v})$ bovine serum albumin. The samples were centrifuged in a microcentrifuge at $10000 \mathrm{~g}, 15 \mathrm{~min}$. The radioactivity in $20 \mu \mathrm{l}$ portions of the supernatants was determined using Ready Solv (Beckman) scintillation fluid and counted in an Intertechnique scintillation counter (7400 c.p.m. was equivalent to $100 \%$.) The data represent mean values of five experiments.
\end{abstract}

\section{Condition}

(1) infected $c w l$
Crude pneumococcal amidase Supernatant from Dp-1

Supernatant from Dp-1 infected $c w 1+$ DTT $(10 \mathrm{mM})$

Uninfected sonicated $c w l$

Uninfected sonicated $c w l$

+ DTT (10 mM)
Radioactivity (c.p.m.) released after:

$\begin{array}{rc}1 \mathrm{~h} & 4 \mathrm{~h} \\ 7400 & 7400 \\ 920 & 7100 \\ 7500 & 7400 \\ & \\ 220 & 560 \\ 200 & 540\end{array}$

Analysis of the lysate of a Dp-1 infected (high m.o.i.) culture for the presence of a murein hydrolase activity yielded the data summarized in Table 1. A substantial increase in a cell wall degrading enzyme activity over that of the residual (i.e. uninfected) control cells was apparent. This activity was greatly stimulated by the addition of dithiothreitol or other reducing agents. No stimulation was detectable in the residual hydrolase activity of uninfected control cell extracts.

These studies suggested that the Dp-1-induced lysis of strain $c w 1$ was mediated by phageassociated lytic activity (PAL). However, additional experiments indicated that the $c w 1$ mutant contained thermolabile autolytic activity and possessed a protein that cross-reacted serologically with antibody against the autolytic enzyme from wild-type pneumococci (unpublished observations). There was, therefore, a possibility that phage-induced lysis was caused by residual amounts of thermolabile autolysin which may have become further stabilized and/or activated by some phage product.

In order to distinguish between those possibilities, further physiological experiments were performed in the Dp-1-infected $c w 1$ mutant. The data shown in Fig. 1 clearly indicated that host bacterial autolysin was capable of overcoming the defective lysis of $c w l$ cultures infected at low m.o.i. A similar experiment was performed with PAL. Figure 3 shows that 'coating' of the mutant bacteria with the phage-associated lysin could also eliminate the phenomenon of defective lysis at low m.o.i. The observed stimulation of lysis by the addition of DTT to this system was also consistent with this conclusion. Further evidence for the participation of the PAL enzyme in Dp-1 induced culture lysis was provided by the observation that the phageinduced lysis of PAL-coated bacteria could be inhibited by the addition of cardiolipin (Fig. 3). No such inhibition was noted with autolysin-coated cells, whereas Dp-1-induced lysis of Dp-1infected (low m.o.i.) $c w l$ cells, coated with either bacterial autolysin or the PAL, were both inhibited by the Forssman antigen (Höltje \& Tomasz, 1976 b).

In order to test if the low m.o.i. defect might be eliminated in strain $c w 1$ under conditions which allow stabilization of the residual bacterial autolytic activity, $c w l$ cultures grown at $30^{\circ} \mathrm{C}$ were infected with Dp-1 at m.o.i. of $1 / 15$. Such cultures were indeed capable of undergoing lysis (not documented) suggesting that the low m.o.i. defect in the $c w l$ cells may be corrected by either the wild-type or the PAL enzyme. 


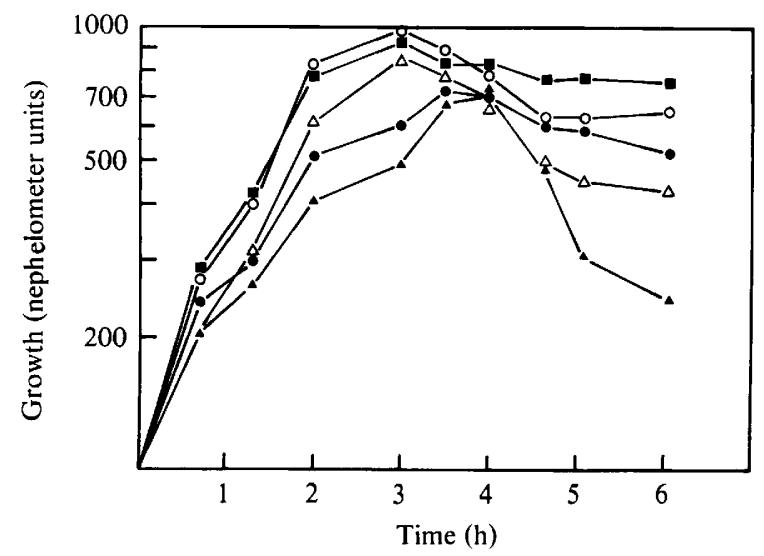

Fig. 3. Phage-induced lysis of PAL-coated mutant cells during infection by DP-1 at low m.o.i. A culture of the autolysis-defective mutant $c w l$ was grown in $\mathrm{C}+\mathrm{Y}$ medium. A portion of this culture was infected with phage Dp-1 at a m.o.i. of 0.02 . The infected culture was distributed into two test tubes, one received no additions $(\square)$, the other received $10 \mathrm{~mm}$-DTT (O).

Another portion of the $c w l$ culture was first 'coated' with purified PAL ( $8 \mu 1$ purified PAL to 2$5 \times 10^{7}$ c.f.u. bacteria $\mathrm{ml}^{-1}$ ), as described by Tomasz \& Waks (1975), and was subsequently infected with Dp-1 at an m.o.i. of 0.02 . This culture was divided in three portions: the first received cardiolipin (O) $\left(100 \mu \mathrm{g} \mathrm{ml}^{-1}\right)$, another tube received no extra additions $(\triangle)$ and $10 \mathrm{mM}$-DTT was added to the last tube (A). Time of infection was at $0 \mathrm{~min}$ in each culture. All five cultures were incubated at $37^{\circ} \mathrm{C}$ and growth and lysis were determined as nephelometric units. The figure represents typical data from one of a series of six experiments.

\section{Expression of PAL activity in Dp-1 infected cultures of the autolysin-defective mutant}

The PAL activity was fully expressed in $c w 1$ cultures treated with 5-fluorodeoxyuridine in spite of the fact that the titre of viable progeny phage was suppressed by about $65 \%$ (Fig. 4).

Addition of streptomycin to a culture of strain $c w l$ at various times after infection revealed that the expression of PAL activity could be prevented up to about $45 \mathrm{~min}$ after infection by inhibition of protein synthesis (Fig. 5).

The autolysin 'helper' phenomenon (i.e. the ability of autolysin-coated bacteria to overcome the defective lysis of $c w 1$ infected at low m.o.i.) suggested that infection with Dp-1 may somehow 'trigger' the activity of the surface-adsorbed enzyme, in a manner analogous to penicillin-induced lysis of such bacteria (Tomasz \& Waks, 1975). For this reason, we tested the effect of DP-1 infection on the synthesis of cell walls. Cell wall synthesis, as assessed by incorporation of trichloroacetic acid precipitable $\left[\right.$ methyl $\left.{ }^{-3} \mathrm{H}\right]$ choline, ceased instantly at the preinfection rate, even though synthesis of protein material apparently continued to increase (as judged by the increase in turbidity).

The role of choline-containing (lysin-sensitive) cell wall in the release of progeny phage

The established importance of teichoic acid choline residues for the susceptibility of pneumococcal cultures to autolysis (Mosser \& Tomasz, 1970) offered another experimental system to test the apparent association between Dp-1 infection and cell wall degradation.

A culture of wild-type (R6) pneumococci was grown in ethanolamine-containing medium. When the culture had reached mid-exponential phase, a small quantity of choline $\left(80 \mathrm{ng} \mathrm{ml}^{-1}\right)$ was added along with $\mathrm{Dp}-1$ at a m.o.i. of 5. (Such cultures have been shown to shift immediately to the utilization of choline for teichoic acid biosynthesis, and the resulting choline-containing polymers quickly appear at the equatorial growth zone of the bacteria.)

Organisms were washed free of unadsorbed phage and resuspended in choline-free, ethanolamine-containing medium and were allowed to grow for a further $3 \mathrm{~h}$ during which time the Dp-1 titre in the supernatant fluid and the growth and/or lysis of the culture was monitored. Such phage-infected cultures did release progeny phage with apparently normal kinetics (Fig. 6) in spite of the fact that there was no detectable lysis of the culture as a whole. Interestingly, the 


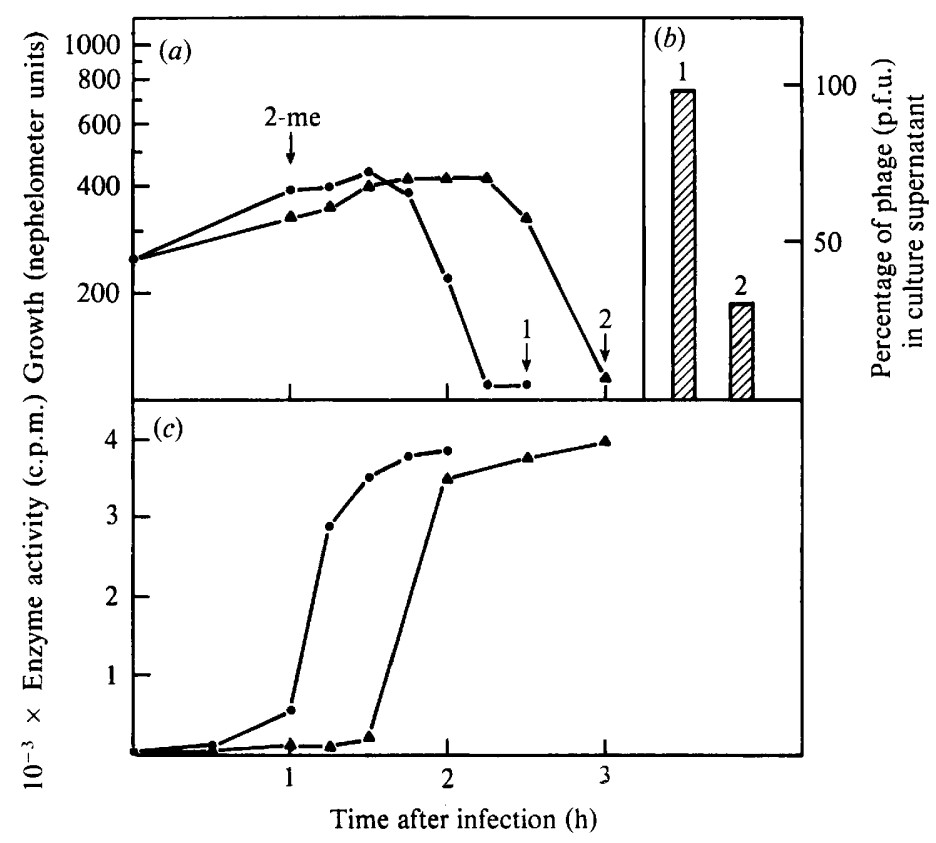

Fig. 4. Effect of 5-fluorodeoxyuridine (FUdr) on the production of phage Dp-1 and on the synthesis of PAL. A culture of $c w l$ was infected with Dp-l (m.o.i. $=5$ ); after $20 \mathrm{~min}$ the culture was divided into two portions, one received $20 \mu \mathrm{g} F \mathrm{Fdr}(\boldsymbol{\Lambda})$ (2) and the other was used as control (O) (1). After $1 \mathrm{~h}$ of incubation at $37^{\circ} \mathrm{C}$ both cultures received $10 \mathrm{mmol} 2$-mercaptoethanol (2-me). (a) Growth and lysis was followed by nephelometry. (b) Total phage produced was determined in both cultures after complete lysis (indicated by the unlettered arrows). (c) The kinetics of appearance of PAL in the supernatants of both cultures. Data represent mean values of five experiments.

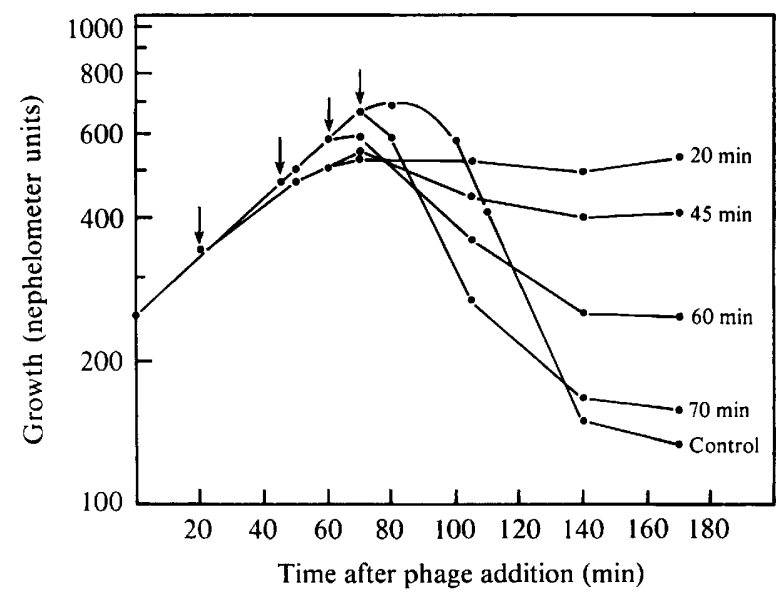

Fig. 5. Prevention of lysis by treatment with streptomycin. A culture of strain $c w l$ was grown in $\mathrm{C}+\mathrm{Y}$ medium and infected with Dp-1 (m.o.i. = 5) at the time 0 . At different times (indicated by the arrows and by the numbers on the curve), samples $\left(10 \mathrm{ml}\right.$ ) were taken and received $100 \mu \mathrm{g}$ streptomycin $\mathrm{ml}^{-1}$. A control culture received phage but no antibiotic. Growth and lysis were followed by the usual method. Data represent mean values from five experiments. 


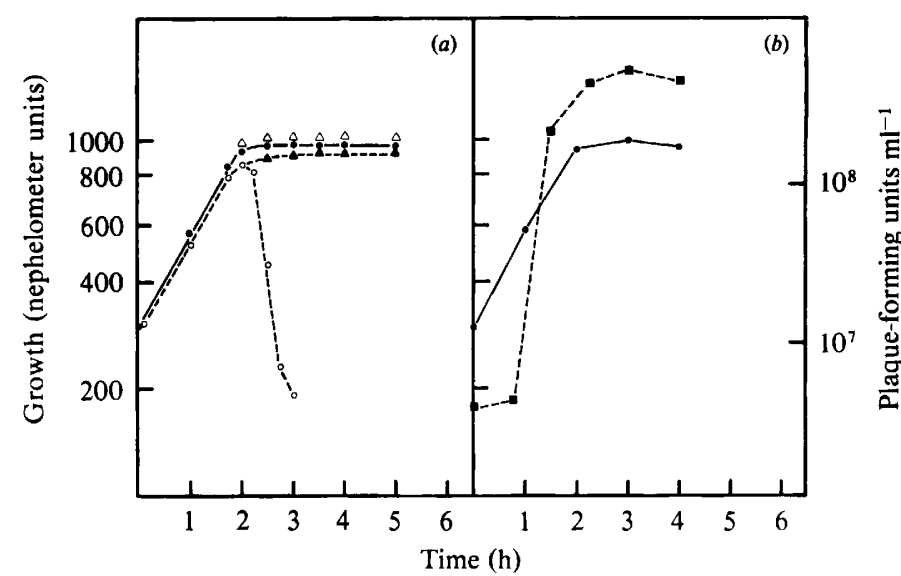

Fig. 6. Response to infection by $\mathrm{Dp}-1$ in ethanolamine-grown cells shifted to choline. A culture of exponentially growing ethanolamine-containing $\left(40 \mu \mathrm{g}\right.$ ethanolamine $\left.\mathrm{ml}^{-1}\right)$ cells received a 'mini-pulse' of choline $\left(0.08 \mu \mathrm{g} \mathrm{ml}^{-1}\right) ; 5 \mathrm{~min}$ later purified bacteriophage $\mathrm{Dp}-1$ was added at m.o.i. $=5$. Incubation was continued at $37^{\circ} \mathrm{C}$ for $20 \mathrm{~min}$. At this time the culture was rapidly cooled at $4{ }^{\circ} \mathrm{C}$ and anti Dp-1 serum was added for $10 \mathrm{~min}$. The sample was divided into two portions, centrifuged, washed $(10000 \mathrm{~g})$ at $4{ }^{\circ} \mathrm{C}$ and resuspended in ethanolamine-containing medium (O), or in the same medium containing $5 \mu \mathrm{g}$ choline $\mathrm{ml}^{-1}(\mathrm{O})$. Control uninfected cultures grown in ethanolamine medium and shifted $(\triangle)$ or not shifted $(\boldsymbol{\Lambda})$ to choline utilization are also shown. (a) Growth (and lysis) were monitored by nephelometry. (b) Depicts the next phase of the experiment: at timed intervals samples were removed from the infected culture that had been resuspended in ethanolamine-containing medium (O). The cells were sedimented by centrifugation $(10000 \mathrm{~g}, 10 \mathrm{~min})$ and the supernatant fluid was titrated for free phage ( $\square$ ). The figure represents typical data from three similarly designed experiments.

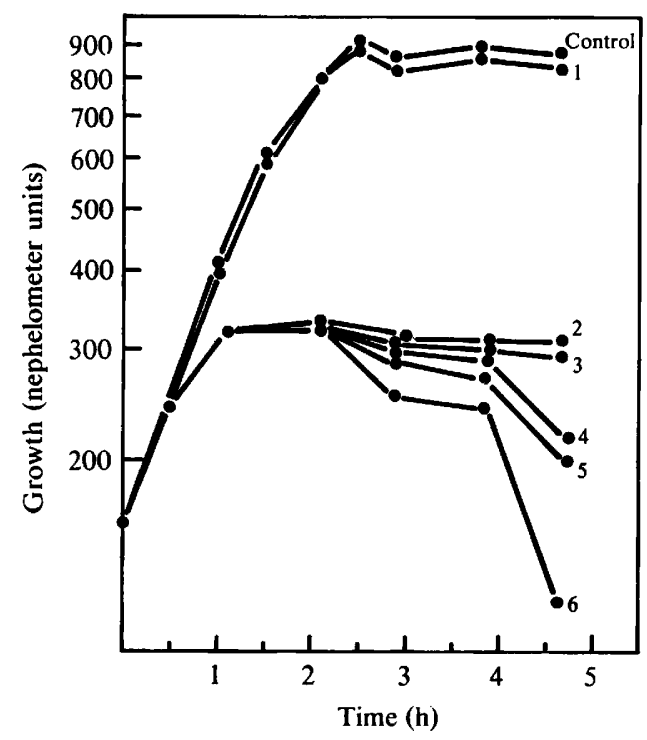

Fig. 7. Sequential treatment of $c w l$ with penicillin and PAL. An exponentially growing culture was treated with benzylpenicillin $\left(0.06 \mu \mathrm{g} \mathrm{m}^{-1}\right)$ at a cell concentration of $4 \times 10^{7}$ c.f.u. $\mathrm{ml}^{-1}$ for $60 \mathrm{~min}$. Then, the culture was divided into five portions (tubes 2 to 6 ): in one incubation with penicillin alone was continued (2), the other four received PAL alone (6) or PAL plus different amounts of cardiolipin: $20 \mu \mathrm{g} \mathrm{ml}^{-1}(5) ; 50 \mu \mathrm{g} \mathrm{ml}^{-1}(4) ; 100 \mu \mathrm{g} \mathrm{ml}^{-1}$ (3). A control culture received no additions at all and tube 1 received only PAL. Data are means of three determinations. 
number of phage particles in the supernatant could be almost doubled by adding a second minipulse of choline to such a culture towards the end of the incubation period (data not included). There was no detectable drop in the turbidity of the culture. However, the addition of a larger quantity of choline $\left(0.5 \mu \mathrm{g} \mathrm{ml}^{-1}\right)$ to the washed, phage-infected particles resulted in a still higher phage yield accompanied by the complete lysis of the infected bacterial culture.

\section{Activity of cell-adsorbed PAL in absence of phage infection}

In view of the similarities between the pneumococcal autolytic enzyme and the phageassociated lysin (PAL), it was of interest to test the activity of PAL adsorbed to the surface of autolysis-defective mutant pneumococci, in the absence of Dp-1 infection. PAL-coated mutant cells behaved like 'phenocopies' of wild-type (i.e. lysis-prone) pneumococci in several situations. In contrast to the uncoated mutant cells (and similarly to the wild-type bacteria), the PALcoated bacteria displayed lysis in the stationary phase of growth (data not included) and, lysis by benzylpenicillin (Fig. 7). Also, penicillin-induced lysis was inhibited by cardiolipin (Fig. 7 lines 3,4 and 5) or by pre-treatment of the cells with chloramphenicol (data not included).

\section{DISCUSSION}

The purpose of these investigations was to continue our studies on the role of murein hydrolase activity in the release of progeny phage and in the phage-induced lysis of Dp-1infected pneumococci. Two puzzling observations have been studied: the apparent inability of Dp-1 to infect an autolysis-defective pneumococcal mutant at low m.o.i., and the complete lysis of the same mutant cultures upon productive infection at higher m.o.i.

The experimental results described confirmed the notion that the 'low multiplicity phenomenon' was related to the autolytic defect in the host cells since coating of the bacteria (prior to infection) with either wild-type bacterial autolysin or the newly detected PAL could allow a productive phage cycle (and eventual culture lysis) at low m.o.i. The possible utilization of the thermolabile residual host enzyme activity (unpublished observations) for phage release was also consistent with the observed stimulation of phage lysis observed at the lower temperature. On the other hand, the elimination of the low multiplicity defect by the addition of DTT implies the activity of the PAL (see Table 1). It seems that the latter activity can appear in the infected $c w l$ cells even under conditions which severely suppress the formation of mature phage particles (5-fluorodeoxyuridine). Addition of streptomycin to the cultures early after infection could also prevent lysis (and phage release). This may indicate that PAL is an early phage function. Alternatively, the suppression of lysis under those conditions may be related to the less well understood, but widely recognized, phenomenon of the suppression of bacterial autolytic systems in cells treated with inhibitors of protein biosynthesis (Tomasz \& Westphal, 1971; Tomasz \& Waks, 1975).

The relationship between the thermolabile residual (host) hydrolase activity present in uninfected $c w 1$ and PAL is not yet completely clear since the possibility that the phage infection somehow further stabilizes and/or activates this enzyme cannot be completely excluded.

A particularly interesting feature of this system is illustrated by experiments in which PAL appeared to replace or mimic some of the function of the pneumococcal autolysin of wild-type bacteria. The Dp-1 infected autolysis-defective mutant $(c w 1)$ was shown to regain rapidly sensitivity to detergent-induced lysis, lysis in the stationary phase and lysis during penicillin treatment. In further similarity to the situation in wild-type (autolysis-prone) cells, penicillininduced lysis of PAL-coated cells could be prevented by treatments with chloramphenicol or with the specific inhibitor of purified PAL, cardiolipin (Garcia et al., 1983).

Further evidence for possible interference with the control of pneumococcal murein hydrolase by phage infection is suggested by lysis of PAL-coated, autolysis-defective mutants in stationary phase or following exposure to benzylpenicillin. Rapid inhibition of cell wall biosynthesis after infection may lead to the triggering of host autolytic enzyme in a manner similar to that described for penicillin treatment (Tomasz \& Waks, 1975).

Partial release of progeny phage from ethanolamine-grown pneumococci in the absence of observable lysis (Fig. 6) requires comment. These experiments can be interpreted as follows: the 
initial choline mini-pulse enabled the majority (or all) of the bacteria to become infected by the high m.o.i. of Dp-1 used. However, subsequent to the successful entry of phage into the host cells, the bacteria revert to utilization of ethanolamine and consequently synthesize cell wall material resistant to the hydrolytic action of both the pneumococcal host autolysin (Tomasz \& Westphal, 1971) and PAL (Garcia et al., 1983). By the end of the incubation in ethanolaminecontaining medium the bacterial cells that inherited the original choline-containing (i.e. lysissensitive) segments of cell wall material must represent a minority of the total population (Tomasz et al., 1975). We suggest that the observed release of progeny phage occurred from these cells, while the rest of the intracellular phage particles remained 'locked' in the ethanolaminecontaining bacteria which did not undergo lysis. However, the application of the second exposure to choline in this experiment resulted in the introduction of lysis-sensitive cell wall material into the majority of the phage infected (and as yet unlysed) bacteria causing further release of progeny bacteriophage and culture lysis. These experiments suggest that the cholinerequirement of Dp-1 infection of pneumococci is due to a dual function of those aminoalcohol residues, first as parts of phage receptors (McDonnell et al., 1975; Lopez et al., 1982) and then as ligands providing a cell wall surface sensitive to the activity of the murein hydrolases that are apparently essential for the release of progeny phage particles from the host bacteria.

We thank Professor Antonio Portoles for his support. This work has been supported by grant 3067-79 of the Comission Asesora para el Desarrollo de la Investigacion Cientifica y Tecnica and by grant AI 16170 from the National Institutes of Health, U.S. Public Health Service. P. G. received a Predoctoral fellowship from Caja de Ahorros y Monte de Piedad de Madrid.

\section{REFERENCES}

Garcia, P., Garcia, E., Ronda, C., Lopez, R. \& TomAsz, A. (1983). A phage-associated murein hydrolase in $S$. pneumoniae infected with bacteriophage Dp-1. Journal of General Microbiology 129, $489-497$.

HöltJE, J. V. \& Tomasz, A. (1975). Lipoteichoic acid: a specific inhibitor of autolysin activity in pneumococcus. Proceedings of the National Academy of Sciences of the United States of America 72, 16901694.

HöltJe, J. V. \& Tomasz, A. (1976a). Purification of the pneumococcal $N$-acetylmuramyl-L-alanine amidase to biochemical homogeneity. Journal of Biological Chemistry 251, 4199-4207.

HöltJe, J. V. \& Tomasz, A. (1976b). Biological effects of lipoteichoic acids. Journal of Bacteriology 124, 1023-1027.

JiANG, R. \& TOMASZ, A. (1981). Genetic transformation of defective autolysis and penicillin tolerance in Streptococcus pneumoniae. In 21 st Interscience Conference on Antimicrobial Agents and Chemotherapy, November 4-6, 1981, abstract no. 505. Washington: American Society for Microbiology.

LACKS, S. (1970). Mutants of Diplococcus pneumoniae that lack deoxyribonucleases and other activities possibly pertinent to genetic transformation. Journal of Bacteriology 101, 373-381.

Lopez, R., Ronda, C., Tomasz, A. \& Portoles, A. (1977). Properties of "diplophage". A lipid-containing bacteriophage. Journal of Virology 24, 201-210

LoPEZ, R., GARCIA, E. \& Ronda, C. (1981). Bacteriophages of Streptococcus pneumoniae. Reviews of Infectious Diseases 3, 212-223.

Lopez, R., Garcia, E., Garcia, P., Ronda, C. \& Tomasz, A. (1982). Choline-containing bacterio- phage in S. pneumoniae. Journal of Bacteriology 151, 1581-1590.

McDonnell, M., Ronda, C. \& Tomasz, A. (1975). Diplophage: a bacteriophage of Diplococcus pneumoniae. Journal of Virology 63, 577-582.

Mosser, J. L. \& Tomasz, A. (1970). Choline-containing teichoic acid as a structural component of pneumococcal cell wall and its role in sensitivity to lysis by an autolytic enzyme. Journal of Biological Chemistry 245, 287-298.

Ronda, C., Lopez, R., TAPIA, A. \& Tomasz, A. (1977). Role of the pneumococcal autolysin (murein hydrolase) in the release of progeny bacteriophage and in the phage-induced lysis of the host cells. Journal of Virology 21, 366-374.

Tomasz, A. (1966). Model for the mechanism controlling the expression of competent state in pneumococcus culture. Journal of Bacteriology 91, 1050-1061.

Tomasz, A. (1970). Cellular metabolism in genetic transformation of pneumococci, requirement for protein synthesis during induction of competence. Journal of Bacteriology 101, 860-871.

ToMasz, A. \& WAKs, S. (1975). Mechanism of action of penicillin: triggering of the pneumococcal autolytic enzyme by inhibitors of cell wall synthesis. Proceedings of the National Academy of Sciences of the United States of America 72, 4162-4166.

Tomasz, A. \& WestPhal, M. (1971). Abnormal autolytic enzyme in a pneumococcus with altered teichoic acid composition. Proceedings of the National Academy of Sciences of the United States of America 68, 2627-2630.

Tomasz, A., Westphal, M., Briles, E. B. \& FletCHER, P. (1975). On the physiological functions of teichoic acids. Journal of Supramolecular Structure 3, $1-16$. 